\title{
Novel Approaches to Surface Analysis and Materials Engineering Using Highly Charged lons
}

A. Hamza, T. Schenkel, A. Barnes and D. Schneider

\section{February 2, 2000}




\section{DISCLAIMER}

This document was prepared as an account of work sponsored by an agency of the United States Government. Neither the United States Government nor the University of California nor any of their employees, makes any warranty, express or implied, or assumes any legal liability or responsibility for the accuracy, completeness, or usefulness of any information, apparatus, product, or process disclosed, or represents that its use would not infringe privately owned rights. Reference herein to any specific commercial product, process, or service by trade name, trademark, manufacturer, or otherwise, does not necessarily constitute or imply its endorsement, recommendation, or favoring by the United States Government or the University of California. The views and opinions of authors expressed herein do not necessarily state or reflect those of the United States Government or the University of California, and shall not be used for advertising or product endorsement purposes.

Work performed under the auspices of the U. S. Department of Energy by the University of California Lawrence Livermore National Laboratory under Contract W-7405-Eng-48.

This report has been reproduced directly from the best available copy.

Available to DOE and DOE contractors from the

Office of Scientific and Technical Information

P.O. Box 62, Oak Ridge, TN 37831

Prices available from (423) 576-8401

http://apollo.osti.gov/bridge/

Available to the public from the National Technical Information Service

U.S. Department of Commerce 5285 Port Royal Rd., Springfield, VA 22161 http://www.ntis.gov/

OR

Lawrence Livermore National Laboratory Technical Information Department's Digital Library http://www.llnl.gov/tid/Library.html 
FY99 LDRD Final Report

\title{
Novel Approaches to Surface Analysis and Materials Engineering Using Highly Charged Ions
}

\author{
Tracking Code: 97-ERD-102
}

\author{
Alex Hamza, Thomas Schenkel, Alan Barnes, and Dieter Schneider \\ Chemistry and Materials Science Directorate \\ Physics and Space Technology Directorate \\ Lawrence Livermore National Laboratory \\ Livermore, CA 94551
}

\section{Summary}

Complex problems in materials science require very sensitive, high spatial resolution $(<100 \mathrm{~nm})$ determination of chemical (molecular) structures in near-surface volumes. Slow, highly charged ions (HCIs) provide a new, unique tool for probing chemical structure on a nanometer scale.

We have explored the potential of these new highly charged ion based techniques in studies of materials with programmatic significance such as high explosives and actinide surfaces. Specifically we are studying HCI based surface analysis techniques (such as secondary ion mass spectrometry, SIMS) that are capable of achieving sensitivity of less than $10^{9}$ atoms $/ \mathrm{cm}^{2}$. In addition, this technique can determine chemical structure and hydrogen concentration. These attributes make this technique especially important to Laboratory missions in enhanced surveillance and nonproliferation.

The unique advantage of HCIs over singly charged ions is the extreme energy density that is deposited into a nanometer-sized near-surface volume at the impact of a single HCI. For example, a $\mathrm{Au}^{69+}$ ion deposits about $0.5 \mathrm{MJ} / \mathrm{cm}^{3}$. This high energy density causes the emission of a large numbers of secondary particles (electrons, ions, neutral atoms, and clusters) from surfaces. The emitted particles act as probes of the energy dissipation mechanism, and their yields are of technological significance.

The HCI-emission microscope concept we developed uniquely combines all three aspects, high spatial resolution with highly sensitive compositional analysis and chemical structure determination. Our experiments have shown that individual HCI impacts lead to copious electron emission, over 200 electrons per incident highly charged ion. In addition, highly charged ion induced secondary ion mass spectrometry (HCI-SIMS) provides considerably more information per ion impact than conventional SIMS. Combining these two phenomena provides a unique tool to study important materials issues necessary for the laboratory to accomplish its missions. 


\section{Accomplishments}

\section{HCI-SIMS}

Quantitative analysis of surfaces and thin films is a crucial problem in materials research. Quantitative accuracy, sensitivity and depth resolution of secondary ion mass spectrometry (SIMS) have been optimized continuously over the last decades. Useful yields, i. e. the number of secondary ions detected per sputtered target atom, are typically in the order of $10^{-2}$ and can be as low as $10^{-6}$. Accurate quantification often has to rely on the use of calibration standards or make use of cross-calibration with independent analytical techniques.

We reported strong electronic sputtering effects for impact of slow $(\sim 1 \mathrm{keV} / \mathrm{u})$ highly charged ions, like $\mathrm{Xe}^{44+}$ and $\mathrm{Au}^{69+}$, on thin insulating films and semi-metallic foils. Atomic and molecular secondary ion yields were found to be increased by over two orders of magnitude for highly charged as compared to singly charged ions at the same kinetic energy. In the case of $\mathrm{Au}^{69+}$ on $\mathrm{B}-\mathrm{SiO}_{2}(50 \mathrm{~nm}$ on $\mathrm{Si})$, at average more than 3 secondary ions were detected per incident highly charged ion. In addition we reported the first application of highly charged ion induced electronic sputtering for quantitative materials analysis.

Publications

T. Schenkel, A. V. Barnes, M. A. Briere, A. Hamza, A. Schach von Wittenau, and D. H. Schneider, "Emission of secondary particles from metals and insulators at impact of slow highly charged ions," Nuclear Instruments and Methods in Physics Research B 125 (1997) 153. UCRL-JC-125769

T. Schenkel, A. V. Hamza, A. V. Barnes, D. H. Schneider, D. S. Walsh, and B. L. Doyle, "Analysis of $\mathrm{B}-\mathrm{SiO}_{2}$ Films by Highly Charged Ion Based Time-of-Flight Secondary Mass Spectrometry and Elastic Recoil Detection," Journal of Vacuum Science and Technology A16 (1998) 1384. UCRL-JC-128724

T. Schenkel, M. Schneider, M. Hattass, M. W. Newman, A. V. Barnes, A. V. Hamza, R. L. Cicero, C. E. D. Chidsey, D. H. Schneider, "Electronic Desorption of Alkyl Monolayers from Silicon by very Highly Charged Ions," Journal of Vacuum Science and Technology, B16 (1998) 3298. UCRL-JC-131064

\section{HCI-emission microscope.}

The past decade has seen the increasingly sophisticated demands of the semiconductor industry for highly sensitive materials characterization at high spatial resolution drive instrument development. An impressive array of instruments is available to achieve very high-resolution lateral imaging of materials (transmission electron microscopy, scanning electron microscopy, scanning tunneling microscopy, etc.). There is an equally impressive array of instruments and techniques available to determine material composition (secondary ion mass spectroscopy, Auger electron spectroscopy, photoelectron spectroscopy, etc.). We reported on a new emission microscopy technique which offers both high spatial resolution and very sensitive compositional analysis, 
simultaneously. This prototype instrument was designed and built to demonstrate the proof-of-principal. We have applied this microscope to the study of hydrogen localization on polycrystalline depleted uranium surfaces.

Publication.

A. V. Hamza, A. V. Barnes, E. Magee, T. Schenkel, and D. H. Schneider, "Highly Charged Ion Based Time-of-Flight Emission Microscope," Reviews of Scientific Instruments, submitted. UCRL-JC-131736

\section{Coincidence Counting Technique}

More then one secondary ion can be detected from the impact of individual highly charged ions like $\mathrm{Th}^{75+}$ on surfaces. By accumulating time-of-flight SIMS cycles event by event we can differentiate impact events requiring the presence of characteristic fingerprint ions. Building spectra with characteristic requirements, we can now see correlations of secondary ions that were emitted from single primary ion impacts. We estimate the emission area of secondary ions to be only $\sim 10 \mathrm{~nm}$ x $10 \mathrm{~nm}$. The uniquely high secondary ion yields enable the probing of chemical structure and homogeneity of complex target surfaces on a nanometer scale.

Highly charged ions are a unique tool for probing of chemical structure on a nanometer length scale. For example we have reported determining surface properties by coincidence counting from tantalum diffusion barrier features that are $25 \mathrm{~nm}$ in width. We have explored the potential of this new technique in studies of materials with programmatic significance such as hydrogen getter technology and high explosive mixtures.

Publications

A. V. Hamza, A. V. Barnes, T. Schenkel, and D. H. Schneider, "Secondary Ion Coincidence in Highly Charged Ion Based Secondary Ion Mass Spectrometry for Process Characterization," Journal of Vacuum Science and Technology A 17 (1999) 303. UCRL-JC-130627

T. Schenkel, K. J. Wu, H. Li, M. W. Newman, A. V. Barnes, and A. V. Hamza, "Analysis of Sub-Micron $\mathrm{Cu}-\mathrm{Ta}-\mathrm{SiO}_{2}$ Structures by Highly Charged Ion SIMS," Journal of Vacuum Science and Technology, B 17 (1999) 2331. UCRL-JC-133731

T. Schenkel, A. V. Hamza, A. V. Barnes, M. W. Newman, G. Machicoane, T. Niedermayr, J. W. McDonald, D. H. Schneider, K. J. Wu, R. W. Odom, “ Surface Analysis by Highly Charged Ion Based Secondary Ion Mass Spectrometry," Physica Scripta T80 (1999) 73. UCRL-JC-132033

IV. Fundamentals of the interaction of slow, highly charged ions with solids.

\section{A. Sputter Yields}

We have measured the sputter yields of solid surfaces interacting with highly charged ions. Sputter yields are fundamental characteristics of the interaction of highly charged ions with surfaces. Important new insights into atomistic mechanisms of the interaction are based on our results. In addition the sputter yields are a fundamentally necessary step in the secondary ion mass spectrometry process. 
We reported the first measurements of the charge-state enhanced sputter yields of materials without known long lived electronic traps, such as self trapped excitons. These results were particularly exciting in the case of semiconductor surfaces.

Publications

T. Schenkel, A. V. Barnes, A. V. Hamza, D. H. Schneider, J. C. Banks, and B. L. Doyle, "Synergy of Electronic Excitations and Elastic Collision Spikes in Sputtering of Heavy Metal Oxides," Physical Review Letters, 80 (1998) 4325. UCRL-JC-129534

T. Schenkel, A. V. Hamza, A. V. Barnes, D. H. Schneider, J. C. Banks, and B. L. Doyle, "Ablation of GaAs by Intense ultrafast electronic excitation on a Nanometer Scale," Physical Review Letters, 81 (1998) 2590. UCRL-JC-130626

T. Schenkel, A. V. Hamza, A. V. Barnes, and D. H. Schneider, "Interaction of Slow, Highly Charged Ions with Surfaces," Progress in Surface Science 61 (1999) 23. UCRL-JC-133730

B. Cluster Ion Emission

Clusters emission phenomena are of scientific and technological interest because of the potential for clusters to form materials with new chemical and physical properties. In addition, studies of the cluster yields due to surface excitation will lead and have led to a better understanding of the excitation mechanism and sputtering process. Thirdly, the increase in cluster ion yield with charge provides chemical structure information from the surface.

Publications

T. Schenkel, A. V. Barnes, A. V. Hamza, and D. H. Schneider, "Cluster Ion Emission upon Slow, Highly Charged Ion Impact,” European Physical Journal D - Clusters and Molecules, 1 (1998) 297. UCRL-JC-127177

A. V. Hamza, T. Schenkel, and A. V. Barnes, "Dependence of Cluster Ion Emission from Uranium Oxide Surfaces on the Charge State of the Incident Slow Highly Charged Ion,” European Physical Journal D, 6 (1999) 83. UCRL-JC-131620

\section{Energy Deposition}

The potential energy of HCI is the sum of the binding energies of the electrons removed when forming the ion. We report the first measurements of the deposition of potential energy into electronic excitations of the surface. The deposition of this potential energy determines the atomic rearrangements that eventually lead to sputtering and structural changes in the solid surface. 
Publication

T. Schenkel A. V. Barnes, T. Niedermayr, M. Hattass, M. W. Newman, G. Machicoane, J. W. McDonald, A. V. Hamza and D. H. Schneider, "Deposition of Potential Energy in Solids by Slow, Highly Charged Ions," Physical Review Letters, 83 (1999) 4273. UCRL-JC-132793

D. Neutralization Times

The time required for HCIs to reach charge state equilibrium determine how fast the potential energy is deposited in the solid surface. This speed determines the increased energy density that is induced in the solid surface and eventually determines the solid response.

We report the first direct determination of the equilibration time in solid matter for HCI, like $\mathrm{Au}^{68+}$, of 7 femtoseconds.

Publications

M. Hattass, T. Schenkel, A. V. Hamza, A. V. Barnes, M. W. Newman, J. W. McDonald, T. Niedermayr, G. Machicoane, and D. H. Schneider, "Charge Equilibration Time in Solids," Physical Review Letters, 82 (1999) 4795. UCRL-JC-132795

\section{E. Energy Loss}

Reduced screening of the nuclear charge of highly charged projectiles in solid surfaces had been proposed to result in increased momentum transfer to target electrons and nuclei. A finite de-excitation time of highly charged ions should result in energy loss enhancements due to pre-charge-state-equilibrium contributions as compared to the energy loss of projectiles that reach a target in charge state equilibrium. We reported the first observations of charge-state dependent energy-loss enhancements of slow, highly charged ions in solids.

Publications

T. Schenkel, M. A. Briere, A. V. Barnes, A. V. Hamza, K. Bethge, H. Schmidt-Böcking, and D. H. Schneider, "Charge Dependent Energy Loss of Slow Heavy Ions in Solids," Physical Review Letters, 79 (1997) 2030. UCRL-JC-127783

T. Schenkel, A. V. Hamza, A. V. Barnes, and D. H. Schneider, "Energy Loss of Slow Highly Charged Ions in Solids," Physical Review A - Rapid Communications, 56(1997) R1701. UCRL-JC-127784

\section{Acknowledgment}

This work was performed under the auspices of the U.S. Department of Energy by University of California Lawrence Livermore National Laboratory under contract No. W7405-Eng-48. 